\title{
Steuern sparen mit der gebundenen Vorsorge (3a)
}

Schöpfen Sie die Vorteile der gebundenen Vorsorge (Säule 3a) bereits voll aus? Angestellte können jährlich bis zu CHF 6739.-, Selbständigerwerbende 20\% ihres Einkommens, max. CHF 33696.-, in die Säule 3 a einzahlen und diese Beiträge voll vom steuerbaren Einkommen abziehen.

Steuern können aber nicht nur während der Laufzeit, sondern auch bei der Auszahlung gespart werden, wenn Sie den Bezug dieser Gelder auf mehrere Jahre verteilen. Wir beraten unsere Kunden unabhängig und neutral. Gemeinsam ermitteln wir Ihre Bedürfnisse und planen Ihre Vorsorge. Weiter begleiten wir Sie bei der Umsetzung und helfen Ihnen, die für Sie geeignete Lösung zu finden.

Bitte senden Sie mir eine kostenlose und unverbindliche Offerte für eine gebundene Vorsorge (Säule 3a):

Gewünschte Jahresprämie

$\square$ 6739.-

$\square$

$\square \quad$ Ich wünsche eine persönliche Beratung. Bitte rufen Sie mich an.

Vorname / Name

Adresse

PLZ / Ort

Geburtsdatum

Telefon Privat / Geschäft

Beste Zeit für einen Anruf

E-Mail-Adresse

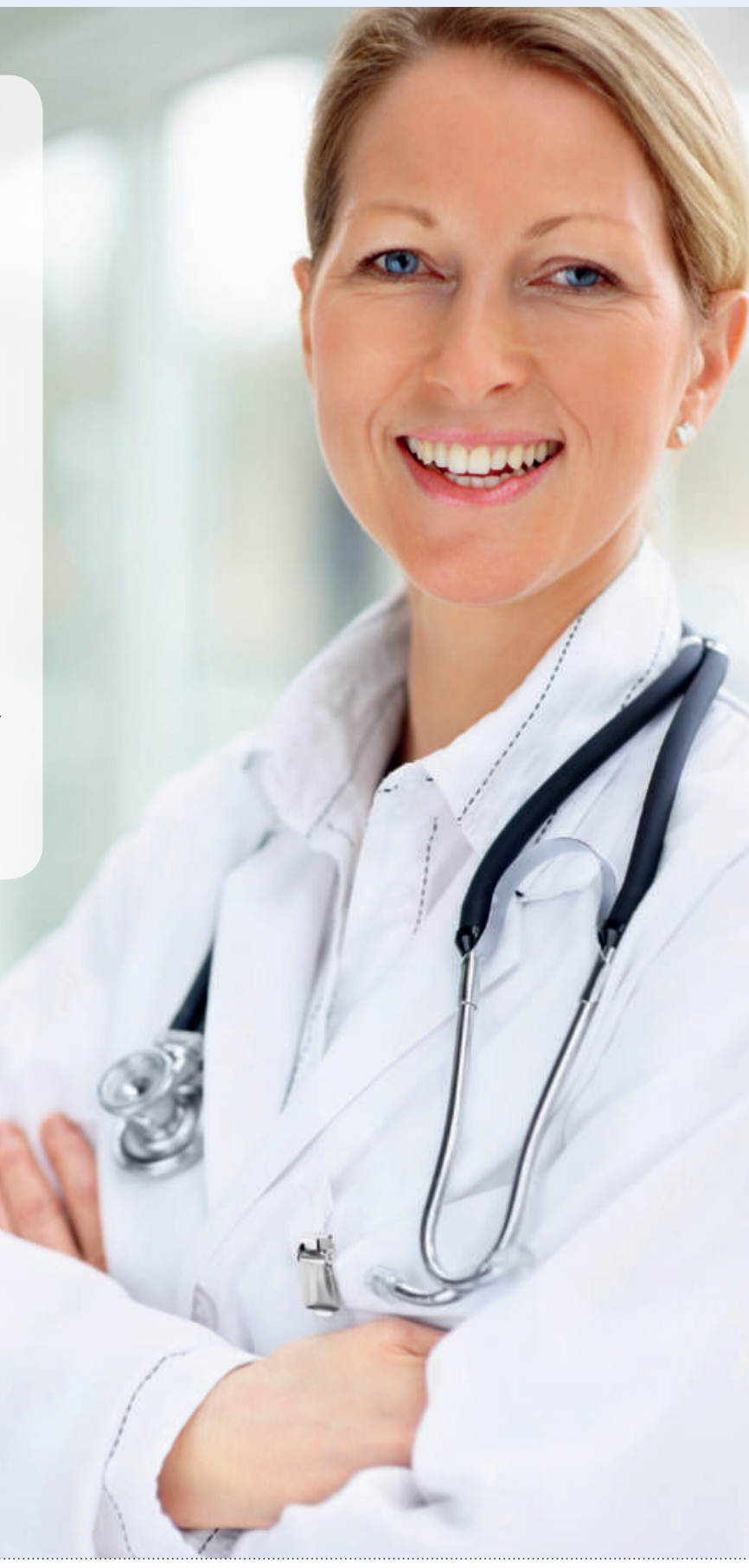

